\title{
ANTIMICROBIAL RESISTANCE GENES AND VIRULENCE GENE ENCODING INTIMIN IN ESCHERICHIA COLI AND ENTEROCOCCUS ISOLATED FROM WILD RABBITS (ORYCTOLAGUS CUNICULUS) IN TUNISIA
}

\author{
Laila BEN SAID ${ }^{1 *}$, Ahlem JOUINI ${ }^{2}$, Ismail FLISS ${ }^{1}$, Carmen TORRES $^{3}$ and Naouel KLIBI ${ }^{4}$ \\ ${ }^{1}$ Institute of Nutrition and Functional Foods, Université Laval, Quebec City, \\ G1V 0A6 Quebec, Canada; ${ }^{2}$ Laboratory of Epidemiology and Veterinary Microbiologie, \\ Pasteur Institute of Tunis, Tunisia; ${ }^{3}$ Area de Bioquímica y Biología Molecular, \\ Universidad de La Rioja, Logroño, Spain; ${ }^{4}$ Laboratoire des Microorganismes et \\ Biomolécules actives, Faculté de Sciences de Tunis, Université de Tunis El Manar, \\ Tunis, Tunisie
}

(Received 7 January 2019; accepted 28 August 2019)

\begin{abstract}
The spread of antimicrobial-resistant bacteria in wildlife must be viewed as a major concern with serious implications for human and animal health. Escherichia coli and enterococcal isolates were recovered from faecal samples of 49 wild rabbits (Oryctolagus cuniculus) on specific media and were characterised using biochemical and molecular tests. For all isolates, antimicrobial susceptibility testing was performed, and resistance genes were detected by PCR. Molecular typing of isolates was carried out by pulsed-field gel-electrophoresis, and E. coli strains were also tested for the presence of intimin (eae) gene characteristic of rabbit enteropathogenic $E$. coli. A total of $34 E$. coli and 36 enterococci [E. hirae $(52.8 \%)$ and E. faecalis $(47.2 \%)]$ were obtained. For E. coli, resistance to tetracycline $(94 \%)$, streptomycin $(62 \%)$, ciprofloxacin $(47 \%)$, trimethoprim-sulphamethoxazole (35\%) and chloramphenicol (6\%) was observed. Resistance to thirdgeneration cephalosporins was detected in one E. coli strain that carried the $b l a_{\mathrm{CMY}-2}$ and $b l a_{\mathrm{TEM}-1}$ genes. Class 1 integrons were detected in eight isolates. For enterococci, resistance to tetracycline $(63.9 \%)$, erythromycin $(30.5 \%)$, streptomycin $(18.2 \%)$, and chloramphenicol $(5.5 \%)$ was detected. The tet $(\mathrm{M})+\operatorname{tet}(\mathrm{L}), \operatorname{erm}(\mathrm{B})$ and ant(6)-Ia genes were identified in thirteen, seven and three resistant Enterococcus strains, respectively. Molecular typing showed a high diversity among our strains. Wild rabbits could represent a reservoir of E. coli, and enterococci carrying antimicrobial resistance genes and $E$. coli additionally carrying the eae gene of enteropathogenic pathotypes could both contaminate the environment. Our finding seems to represent the first report of eae-positive $E$. coli in wild rabbits.
\end{abstract}

Key words: Wild rabbit, antimicrobial resistance, enterococci, E. coli, intimin, third-generation cephalosporin resistance

\footnotetext{
*Corresponding author; E-mail: laila.ben-said.1@ulaval.ca; Phone: 001 (418) 656-2131
} 
Commensal bacteria constitute a source of antimicrobial resistance genes. When they are released into the environment through the faecal material of animals and humans, they can disseminate in different ecosystems, contaminate food products, be transmitted by the food chain, and so reach the intestinal tract of humans (Franz et al., 1999). These microorganisms are considered important as 'indicator bacteria' in order to track the evolution of antibiotic resistance in different ecosystems (Van den Bogaard et al., 2000). Escherichia coli and Enterococcus are also regarded as opportunistic human pathogens, because they are implicated in a wide diversity of infections, and they might act as reservoirs of antimicrobial resistance genes that could be transmitted to other pathogenic bacteria (Guardabassi et al., 2004). Thus, they might represent a worldwide problem with large repercussions in public health (Van den Bogaard et al., 2000). Wild animals are of importance in relation to antibiotic resistance in several different ways. In fact, many human activities such as human and veterinary clinical settings, farms, landfills and wastewater may give rise to interactions with wildlife, which may have a direct association with the antibiotic resistance profiles of the intestinal bacteria of wild animals in a certain geographic location (Guardabassi et al., 2004; Sayah et al., 2005; Santos et al., 2013). Added to that, wild animal populations could be a possible reservoir of antibiotic-resistant bacteria, and the contact with species of game hunted for their meat may transfer multidrugresistant bacteria to humans or livestock, which provides a biological mechanism for the increase in antibiotic resistance genes in human populations (Sayah et al., 2005; Allen et al., 2010). In Tunisia, the wild rabbit (Oryctolagus cuniculus) represents an important species since it is part of the human food chain. Interaction between wild rabbits and the surrounding ecosystem may represent a source of bacterial dissemination through the environment. To our knowledge, scarce information is available regarding the characteristics of E. coli and Enterococcus isolates of wild rabbit origin (Figueiredo et al., 2009; Silva et al., 2010; Marinho et al., 2014), and no data exist in Tunisia. Therefore, the aim of this study was to analyse the prevalence of E. coli and Enterococcus spp. strains in wild rabbits, as well as the phenotypes and genotypes of antibiotic resistance in recovered isolates in order to evaluate the role of wild rabbits as reservoirs of antibiotic resistance genes.

\section{Materials and methods}

\section{Sample collection, isolation and identification of bacterial strains}

Forty-nine wild rabbits were collected in Southern Tunisia during the rabbit hunting season (in October and November 2016) for human consumption. Swabs of the rectal stumps were collected just when the rabbits were captured. They were transported to the laboratory at $4{ }^{\circ} \mathrm{C}$ and were kept refrigerated and processed within $6 \mathrm{~h}$. Faecal samples were added to $5 \mathrm{ml}$ of peptone water, being 
incubated at $37^{\circ} \mathrm{C}$ for $24 \mathrm{~h}$. After that, several dilutions of the enrichment broth were seeded in a specific medium.

For E. coli isolation, the dilutions were seeded in MacConkey agar plates and incubated at $37^{\circ} \mathrm{C}$ for $24 \mathrm{~h}$. One colony per sample with typical E. coli morphology was selected and identified by classical biochemical methods (indole, citrate and urease), and confirmed by PCR amplification of the uid gene (uid-F: 5'-ATCACCGTGGTGACGCATGTCGC-3'; uid-R: 5'-CACCACGATGCCAT GTTCATCTGC-3').

Additionally, for enterococcal isolation, the dilutions were seeded on Slanetz-Bartley agar plates, that were incubated at $37^{\circ} \mathrm{C}$ for $48 \mathrm{~h}$. One colony per plate, with typical enterococcal morphology, was picked from each plate and streaked onto BHI agar plates. The isolates were initially characterised as enterococci based on biochemical tests, including catalase reaction, hydrolysis of esculin in the presence of bile, and capacity to grow in hypersaline medium. The species identification was confirmed by PCR, using primers and conditions for the different enterococcal species (Torres et al., 2003).

\section{Antibiotic susceptibility testing}

The antimicrobial susceptibility patterns of the E. coli isolates were determined by the disk diffusion test for 16 antimicrobials (in $\mu \mathrm{g} /$ disk) [ampicillin (10), amoxicillin + clavulanic acid (20/10), cefoxitin (30), cefotaxime (30), ceftazidime (30), aztreonam (30), imipenem (10), gentamicin (10), amikacin (30), tobramycin (10), streptomycin (10), ciprofloxacin (5), sulphamethoxazole + trimethoprim (SXT) (1.25/23.75), tetracycline (30), and chloramphenicol (30)] according to the Clinical and Laboratory Standard Institute guidelines (CLSI, 2017). Escherichia coli ATCC 25922 was used as a quality control strain. The screening for extendedspectrum beta-lactamase (ESBL) producing E. coli was performed by the double disk synergy test using disks containing amoxicillin/clavulanic acid on MuellerHinton agar plate at a $30-\mathrm{mm}$ distance from the indicator drugs: ceftazidime $(30 \mu \mathrm{g})$ and cefotaxime (30 $\mu \mathrm{g})$ (CLSI, 2017). Additionally, susceptibility testing of the enterococcal isolates was performed for the following antimicrobials (in $\mu \mathrm{g} /$ disk): ampicillin (10), vancomycin (30), teicoplanin (30), chloramphenicol (30), tetracycline (30), pristinamycin (15) erythromycin (15), ciprofloxacin (5), gentamicin (120) and streptomycin (300) (CLSI, 2017). Enterococcus faecalis strain ATCC 29212 was used for quality control.

\section{Detection of antibiotic resistance genes and $\mathrm{E}$. coli intimin (eae) gene by PCR}

The resistant $E$. coli isolates were tested by PCR to detect the following genes: tet(A) and tet(B) genes in all tetracycline-resistant isolates, bla $a_{\mathrm{TEM}}$ gene in ampicillin-resistant isolates, and $b l a_{\mathrm{CTX}-\mathrm{M}}$ and $b l a_{\mathrm{CMY}-2}$ genes in cephalosporinresistant isolates. The presence of the intIl gene encoding the integrase of class 1 
integrons was analysed by PCR in SXT-resistant isolates. The identification of these genes was performed using specific primers and conditions (Sáenz et al., 2004; Ben Said et al., 2016).

On the other hand, the following resistance genes were tested by PCR in resistant enterococci isolates, using specific primers and conditions (Klibi et al., 2013a): $\operatorname{erm}$ (B) (in erythromycin-resistant isolates), $\operatorname{tet}(\mathrm{M})$ and tet(L) (in tetracycline-resistant isolates), ant(6)-Ia (in streptomycin-resistant isolates), and cat(A) (in chloramphenicol-resistant isolates).

Molecular typing by pulsed field gel electrophoresis (PFGE) and detection of eae virulence gene

Molecular typing by PFGE of E. coli and Enterococcus isolates was performed as described previously (Sáenz et al., 2004; López et al., 2009). The resulting restriction patterns were analysed by a visual method and by the GelCompar II software using the UPGMA algorithm (Turabelidze et al., 2000). Moreover, the presence of the eae virulence gene [encoding intimin of enteropathogenic E. coli (EPEC)] was tested in all E. coli isolates by PCR as described by Alonso et al. (2017).

\section{Results and Discussion}

\section{Isolation of bacteria}

Escherichia coli isolates were recovered on MacConkey agar plates in 34 of the 49 rabbit faecal samples $(69 \%)$, while Enterococcus strains were obtained from 36 of the samples analysed (73.5\%). Enterococcus hirae was the most prevalent enterococcal species detected $(52.8 \%, 19 / 36)$ followed by E. faecalis $(47.2 \%$, 17/36). The high incidence of $E$. hirae, in comparison with the incidence of $E$. faecalis, was in contrast with data previously reported about the predominance of E. faecalis and E. faecium among faecal enterococci of both farmed and wild rabbits (Linaje et al., 2004; Silva et al., 2010) and among those from other wild animals, pets and poultry (Butaye et al., 2001; Poeta et al., 2005, 2006; Jackson et al., 2010; Santos et al., 2013). The presence of $E$. hirae in high proportion was also found among faecal enterococci isolated from camels in arid regions of Tunisia (Klibi et al., 2013a).

\section{Antimicrobial resistance among E. coli}

Analysis of the antimicrobial susceptibility of $E$. coli isolates showed a high frequency of resistance to tetracycline (94\%) and streptomycin (62\%), which concurred with other studies carried out on wild animals (Costa et al., 2008), food-producing animals (Sáenz et al., 2001), pigs (Teshager et al., 2000) and foods of animal origin (Jouini et al., 2009). Dotto et al. (2014) previously re- 
ported very high resistance rates $(>90 \%)$ for tetracycline and streptomycin in enterococci recovered from wild and farmed rabbits, although other authors reported lower rates in E. coli isolates from wild rabbits (Silva et al., 2010; Marinho et al., 2014). Lower resistance frequencies were recorded to ciprofloxacin (47\%), trimethoprim-sulphamethoxazole (35\%) and chloramphenicol $(6 \%)$ (Table 1). The rates of resistance for these antibiotics were higher than those reported in wild animals (Costa et al., 2008; Marinho et al., 2014). Differences in resistance percentages could be explained by the difference of the geographic localisation of the wildlife populations studied (Costa et al., 2008).

Table 1

Distribution of antibiotic resistance in E. coli and Enterococcus spp. strains isolated from wild rabbits

\begin{tabular}{|c|c|c|c|}
\hline \multirow[b]{2}{*}{ Antibiotic used } & \multirow{2}{*}{$\begin{array}{l}\text { Number of } \\
\text { resistant } \\
\text { E. coli strains } \\
(\mathrm{n}=34)\end{array}$} & \multicolumn{2}{|c|}{ Number of resistant Enterococcus strains } \\
\hline & & $\begin{array}{l}\text { E. hirae } \\
(\mathrm{n}=19)\end{array}$ & $\begin{array}{l}\text { E. faecalis } \\
(\mathrm{n}=17)\end{array}$ \\
\hline Tetracycline & $32(94 \%)$ & $13(68 \%)$ & $10(59 \%)$ \\
\hline Streptomycin & $21(62 \%)$ & - & - \\
\hline Ciprofloxacin & $16(47 \%)$ & 0 & 0 \\
\hline Sulphamethoxazole + trimethoprim & $12(35 \%)$ & - & - \\
\hline Chloramphenicol & $2(6 \%)$ & 0 & $2(12 \%)$ \\
\hline Ampicillin & $1(3 \%)$ & 0 & 0 \\
\hline Cefoxitin & $1(3 \%)$ & - & - \\
\hline Cefotaxime & $1(3 \%)$ & - & - \\
\hline Ceftazidime & $1(3 \%)$ & - & - \\
\hline Aztreonam & $1(3 \%)$ & - & - \\
\hline Imipenem & 0 & - & - \\
\hline Amoxicillin + clavulanic acid & 0 & - & - \\
\hline Gentamicin $(10 \mu \mathrm{g})$ & 0 & - & - \\
\hline Amikacin & 0 & - & - \\
\hline Tobramycin & 0 & - & - \\
\hline Erythromycin & - & $1(5 \%)$ & $10(59 \%)$ \\
\hline Vancomycin & - & 0 & 0 \\
\hline Teicoplanin & - & 0 & 0 \\
\hline Streptomycin & - & 0 & $6(35 \%)$ \\
\hline Gentamicin $(120 \mu \mathrm{g})$ & - & 0 & 0 \\
\hline Pristinamycin & - & 0 & 0 \\
\hline
\end{tabular}

Dashes mean that the antibiotic was not tested

Multiresistance to three or more different classes of antibiotics was observed in fifteen E. coli isolates (44\%) (Table 2). Even though wild rabbits were not subjected to the selective pressure associated with the extensive use of antimicrobial drugs for food-producing animals, these high rates of multiresistance found in Tunisian wildlife are worrying. The acquisition of antibiotic-resistant 
E. coli strains by wild rabbits could be related to the interactions with farm wastes (Cole et al., 2005; Guerrero-Ramos et al., 2016). All E. coli strains resistant to tetracycline harboured the tet(A) gene, in association with $\operatorname{tet}(\mathrm{B})$ in six strains, which indicates that the main mechanism of tetracycline resistance in wild rabbit E. coli isolates is by active efflux (Silva et al., 2010). Plasmid-mediated quinolone resistance gene aac(6')-Ib-cr was identified in one E. coli strain resistant to fluoroquinolones. The gene int 1 encoding class 1 integrase was detected in eight strains resistant to trimethoprim/sulphamethoxazole; only one type of arrangement was detected in integron-positive isolates, which harboured the gene aadA1 encoding resistance to streptomycin. Resistance to broad-spectrum cephalosporins and ampicillin was detected in only one E. coli strain, which harboured the genes $b l a_{\mathrm{TEM}-1}$ and $b l a_{\mathrm{CMY}-2}$ encoding for resistance to ampicillin and cephalosporins, respectively. CMY-2 was detected in Tunisia in strains isolated from wastewater (Ben Said et al., 2016), foods of animal origin (Ben Slama et al., 2010) and from food-producing animals (Ben Sallem et al., 2012). Table 3 shows the antimicrobial resistance genes detected in E. coli strains. However, none of the $E$. coli isolates were found to be ESBL producers, when the double disc diffusion test was performed for screening.

\section{Table 2}

Multiresistant phenotypes detected among E. coli and Enterococcus isolates obtained from wild rabbits

\begin{tabular}{|c|c|c|}
\hline Species & Multiresistant phenotypes $^{\mathrm{a}}$ & Number of isolates \\
\hline \multirow[t]{5}{*}{ E. coli } & AMP FOX CTX CAZ AZM STR CIP TET & $1^{\mathrm{b}}$ \\
\hline & STR CIP SXT TET & 9 \\
\hline & STR SXT TET & 2 \\
\hline & CIP SXT TET & 1 \\
\hline & CIP STR TET & 2 \\
\hline \multirow[t]{3}{*}{ E. faecalis } & STR ERY TET CHL & 1 \\
\hline & STR ERY TET & 4 \\
\hline & ERY TET CHL & 1 \\
\hline
\end{tabular}

${ }^{a}$ CTX: cefotaxime; CAZ: ceftazidime; AMP: ampicillin; AZM: aztreonam; CIP: ciprofloxacin; FOX: cefoxitin; STR: streptomycin; TET: tetracycline; SXT: sulphamethoxazole + trimethoprim; STR: streptomycin; TET: tetracycline; ERY: erythromycin; CHL: chloramphenicol; ${ }^{\mathrm{b}}$ This isolate carried the gene encoding CMY-2 beta-lactamase

\section{Resistance among Enterococcus isolates}

Antibiotic resistance was detected in 75\% (27/36) of enterococcal strains recovered from wild rabbits. High rates of resistance were observed to tetracycline (TET-R; 63.9\%) and erythromycin (ERY-R; 30.5\%). These frequencies are higher than those reported by Silva et al. (2010) from wild rabbits. Nevertheless, 
Guerrero-Ramos et al. (2016) reported a similar rate of TET-R and a higher rate of ERY-R from wild game meat in Spain. Only two E. faecalis isolates were resistant to chloramphenicol (5.5\%) (Table 1).

Table 3

Antibiotic resistance genes detected in E. coli and Enterococcus spp. strains recovered from wild rabbits

\begin{tabular}{llcl}
\hline Species & \multicolumn{1}{c}{ Antibiotics } & $\begin{array}{c}\text { Number of } \\
\text { resistant } \\
\text { strains }\end{array}$ & \multicolumn{1}{c}{$\begin{array}{c}\text { Resistance gene and } \\
\text { integron detected } \\
\text { (number) }\end{array}$} \\
\hline E. coli & $\begin{array}{l}\text { Ampicillin, cefoxitin, cefotaxime, } \\
\text { ceftazidime } \\
\text { Tetracycline }\end{array}$ & 1 & bla $_{\mathrm{TEM}-1, \text { bla }_{\mathrm{CMY}-2}}$ \\
& Ciprofloxacin & 32 & $\operatorname{tet}(\mathrm{A})(26), \operatorname{tet}(\mathrm{A})+\operatorname{tet}(\mathrm{B})(6)$ \\
& Sulphamethoxazole + trimethoprim & 16 & $\operatorname{aac}(6)-\mathrm{Ib}-\operatorname{cr}(1)$ \\
& Tetracycline & 12 & $\operatorname{int1}(8)$ \\
\hline \multirow{2}{*}{ faecalis } & Erythromycin & 10 & $\operatorname{tet}(\mathrm{M})(2), \operatorname{tet}(\mathrm{M})+\operatorname{tet}(\mathrm{L})(8)$ \\
& Streptomycin & 10 & $\operatorname{erm}(\mathrm{B})(6)$ \\
& Tetracycline & 6 & $\operatorname{ant}(6)-\mathrm{Ia}(3)$ \\
\hline E. hirae & Erythromycin & 13 & $\operatorname{tet}(\mathrm{M})(1), \operatorname{tet}(\mathrm{M})+\operatorname{tet}(\mathrm{L})(5)$ \\
& & 1 & $\operatorname{erm}(\mathrm{B})(1)$
\end{tabular}

All enterococcal isolates were sensitive to ampicillin, vancomycin and teicoplanin. This is in agreement with the results of another study that noted the absence of VRE in wild rabbits (Silva et al., 2010). Nevertheless, other authors have found VRE in food-producing animals, including rabbits (López et al., 2009), wild rabbits (Figueiredo et al., 2009), in wild animals in Portugal (Poeta et al., 2005) and in wild meat game in Spain (Guerrero-Ramos et al., 2014). In Tunisia, acquired resistance to vancomycin has been recently described in the hospital setting, and in wild birds (Elhani et al., 2014; Klibi et al., 2015b).

High-level resistance to streptomycin (HLR-S) was detected in $18.2 \%$ and $12.1 \%$ of enterococcal strains, respectively. None of the strains presented a highlevel resistance to gentamicin (HLR-G). High-level resistance to aminoglycosides was also found in clinical settings (Klibi et al., 2006), meat products (Klibi et al., 2013b; Guerrero-Ramos et al., 2016), as well as in healthy humans, pets and poultry (Poeta et al., 2006). Multiresistance to three or more different families of antibiotics was observed in six E. faecalis strains (16.7\%) (Table 2).

The acquisition of antibiotic resistance could be explained by a possible exposure in the woodlands to faecal material from wild animals such as wild birds or even from humans (Allen et al., 2010). Moreover, wild rabbits as herbivorous animals could consume contaminated vegetation or water, which supports the hypothesis that antibiotic pressures exist even in natural environments (Da Costa et al., 2013). 
The presence of antibiotic resistance genes was studied by PCR in all resistant enterococci (Table 3$)$. The combination of tet $(\mathrm{M})+\operatorname{tet}(\mathrm{L})$ genes was found in thirteen strains resistant to tetracycline, while three strains harboured only tet(M). These findings are in accordance with the results of other studies that have shown that the tet $(\mathrm{M})$ gene is frequently found in enterococcal strains of different origins (Huys et al., 2004). The erm(B) gene, conferring resistance to erythromycin, was detected in seven strains. The predominance of the erm(B) gene is consistent with the findings of Santos et al. (2013) related to enterococci isolated from wild animals. Nevertheless, other mechanisms of resistance could be present in those isolates in which macrolide resistance genes were not found. The gene ant(6)-Ia, responsible for resistance to streptomycin, was detected in three strains. These genes were also found in previous reports among HLR-S and HLR-G enterococcal isolates from food-producing animals, vegetables, and farm environments in Tunisia (Klibi et al., 2015a; Ben Said et al., 2015). The gene cat(A) was not detected among our two chloramphenicol-resistant isolates, which suggests that other mechanisms of resistance may be present in these isolates.

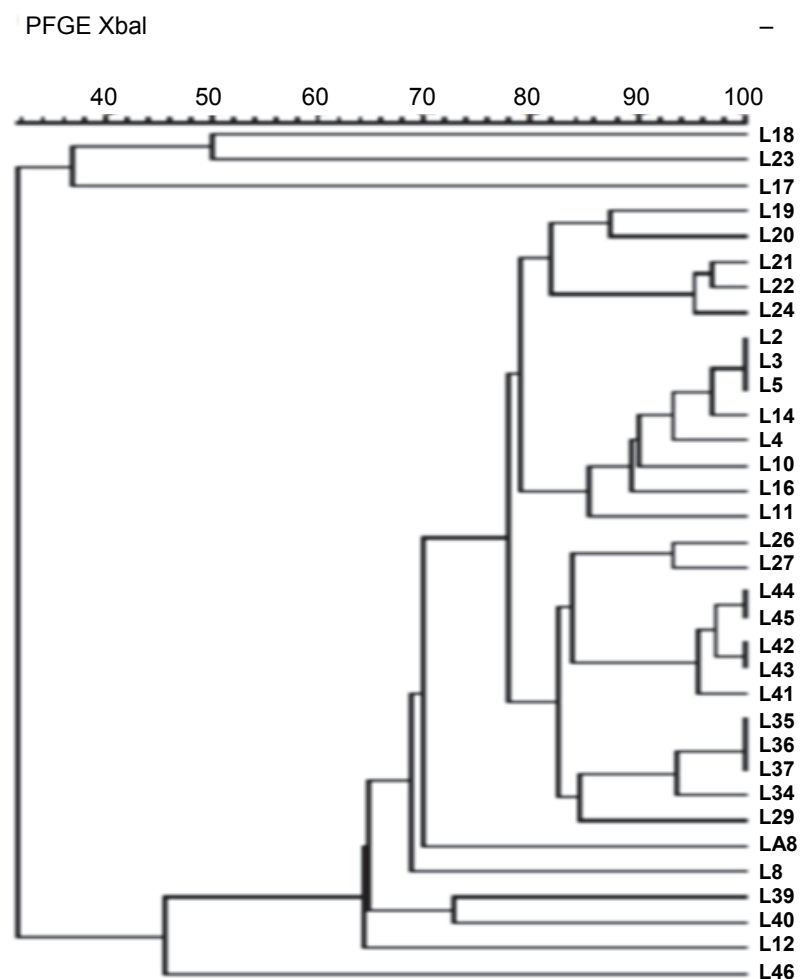

Fig. 1. Dendrogram based on XbaI-PFGE patterns. The GelCompar software (Applied Maths,

Kortrijk, Belgium) was used to register macrorestriction patterns and clustering analysis was performed using Dice similarity coefficient and the unweighted-pair group method with arithmetic mean (UPGMA) among E. coli isolates 


\section{Virulence and molecular typing}

The virulence gene eae was detected in six isolates (LA8, L4, L5, L20, L21 and L22) among the $34 \mathrm{E}$. coli strains tested (17.6\%). This gene encodes intimin, a protein characteristic of enteropathogenic $E$. coli (EPEC) strains, involved in the induction of attaching and effacing $E$. coli (AEEC) lesions in the intestine and causing diarrhoea in rabbits (Ritchie et al., 2003). The gene eae was detected in $E$. coli of wild animals (wild boar, deer and owl) in a previous study (Alonso et al., 2017); nevertheless, eae was not detected in wild rabbits and hares in another study (Dotto et al., 2014), even though some of the strains came from rabbits with a diarrhoeic syndrome. The origin of the eae-positive $E$. coli isolates in our study is not known, although dissemination in the environment could occur. Our finding seems to represent the first report of eae-positive $E$. coli in wild rabbits.

Molecular typing by PFGE showed a high level of diversity, 28 different pulsotypes were observed among 34 E. coli isolates (Fig. 1). For Enterococcus, macrorestriction by SmaI enzyme revealed a genomic diversity for E. faecalis, with 12 different pulsotypes detected among seventeen isolates. However, we have noticed a clonality in E hirae strains; in fact, only five pulsotypes were detected among nineteen isolates.

In conclusion, this is the first study in Tunisia showing that wild rabbits could represent a reservoir of E. coli and Enterococcus isolates carrying antimicrobial resistance genes, which contributes to the spread of antimicrobial resistance into the environment. The use of wild rabbits as a food source for several animals and in the human diet facilitates the transfer of these resistant bacteria to other animals or even to humans. The high incidence of antibiotic resistance found in wild rabbits in the present study raises the question of where these antibiotic-resistant strains originated from. Their origin could be related to the interaction with farm waste, the exposure to faecal material of farm or wild animals and the consumption of contaminated water or vegetation. The same could be postulated for the origin of eae-positive $E$. coli. Further studies are needed to determine the prevalence of resistance and virulence genes of $E$. coli and enterococci in different ecosystems, especially in wildlife.

\section{Acknowledgement}

This work was supported by the Tunisian Ministry of Higher Education and Scientific Research.

\section{References}

Allen, H. K., Donato, J., Wang, H. H., Cloud-Hansen, K. A., Davies, J. and Handelsman, J. (2010): Call of the wild: antibiotic resistance genes in natural environments. Nat. Rev. Microbiol. 8, 251-259. 
Alonso, C. A., Mora, A., Díaz, D., Blanco, M., González-Barrio, D., Ruiz-Fons, F., Simón, C., Blanco, J. and Torres, C. (2017): Occurrence and characterization of stx and/or eaepositive Escherichia coli isolated from wildlife, including a typical EPEC strain from a wild boar. Vet. Microbiol. 207, 69-73.

Ben Said, L., Jouini, A., Alonso, C. A., Klibi, N., Dziri, R., Boudabous, A., Ben Slama, K. and Torres, C. (2016): Characteristics of extended-spectrum $\beta$-lactamase (ESBL) and pAmpC beta-lactamase-producing Enterobacteriaceae of water samples in Tunisia. Sci. Total Environ. 550, 1103-1109.

Ben Said, L., Klibi, N., Dziri, R., Borgo, F., Boudabous, A., Ben Slama, K. and Torres, C. (2015): Prevalence, antimicrobial resistance and genetic lineages of Enterococcus spp. from vegetable food, soil and irrigation water in farm environments in Tunisia. J. Sci. Food Agric. 96, 1627-1633.

Ben Sallem, R., Ben Slama, K., Sáenz, Y., Rojo-Bezares, B., Estepa, V., Jouini, A., Gharsa, H., Klibi, N., Boudabous, A. and Torres, C. (2012): Prevalence and characterization of extended-spectrum beta-lactamase (ESBL)- and CMY-2-producing Escherichia coli isolates from healthy food-producing animals in Tunisia. Foodborne Pathog. Dis. 9, 1137-1142.

Ben Slama, K., Jouini, A., Ben Sallem, R., Somalo, S., Sáenz, Y., Estepa, V., Boudabous, A. and Torres, C. (2010): Prevalence of broad-spectrum cephalosporin-resistant Escherichia coli isolates in food samples in Tunisia and characterization of integrons and antimicrobial resistance mechanisms implicated. Int. J. Food. Microbiol. 137, 281-286.

Butaye, P., Devriese, L. A. and Haesebrouck, F. (2001): Differences in antibiotic resistance patterns of Enterococcus faecalis and Enterococcus faecium strains isolated from farm and pet animals. Antimicrob. Agents Chemother. 45, 1374-1378.

CLSI (2017): Performance Standards for Antimicrobial Susceptibility Testing. Twenty-fifth Informational Supplement. CLSI Document, M100-S25.

Cole, D., Drum, D. J. V., Stallknecht, D. E., White, D. G., Lee, M. D., Ayers, S., Sobsey, M. and Maurer, J. J. (2005): Free-living Canada geese and antimicrobial resistance. Emerg. Infect. Dis. 11, 935-938.

Costa, D., Poeta, P., Sáenz, Y., Vinué, L., Coelho, A., Matos, M., Rojo-Bezares, B., Rodrigues, J. and Torres, C. (2008): Mechanisms of antibiotic resistance in Escherichia coli isolates recovered from wild animals. Microb. Drug Resist. 14, 71-77.

Da Costa, P. M., Loureiro, L. and Matos, A. J. F. (2013): Transfer of multidrug resistant bacteria between intermingled ecological niches: the interface between humans, animals and the environment. Int. J. Environ. Res. Public Health 10, 278-294.

Dotto, G., Giacomelli, M., Grilli, G., Ferrazzi, V., Carattoli, A., Fortini, D. and Piccirillo, A. (2014): High prevalence of oqx $\mathrm{AB}$ in Escherichia coli isolates from domestic and wild lagomorphs in Italy. Microb. Drug Resist. 20, 118-123.

Elhani, D., Klibi, N., Dziri, R., Ben Hassan, M., Asli, M. S., Ben Said, L., Mahjoub, A., Ben Slama, K., Jemli, B., Bellaj, R., Barguellil, F. and Torres, C. (2014): vanA-containing E. faecium isolates of clonal complex $\mathrm{CC} 17$ in clinical and environmental samples in a Tunisian hospital. Diagn. Microbiol. Infect. Dis. 79, 60-63.

Figueiredo, N., Radhouani, H., Gonçalves, A., Rodrigues, J., Carvalho, C., Igrejas, G. and Poeta, P. (2009): Genetic characterization of vancomycin-resistant enterococci isolates from wild rabbits. J. Basic. Microbiol. 49, 491-494.

Franz, C. M. A. P., Holzapfel, W. H. and Stiles, M. E. (1999): Enterococci at the crossroads of food safety? Int. J. Food. Microbiol. 47, 1-24.

Guardabassi, L., Schwarz, S. and Lloyd, D. H. (2004): Pet animals as reservoirs of antimicrobialresistant bacteria. J. Antimicrob. Chemother. 54, 321-332.

Guerrero-Ramos, E., Cordero, J., Molina-González, D., Poeta, P., Igrejas, G., Alonso-Calleja, C. and Capita, R. (2016): Antimicrobial resistance and virulence genes in enterococci from wild game meat in Spain. Food. Microbiol. 53, 156-164. 
Huys, G., D’Haene, G. K., Collard, J. M. and Swings, J. (2004): Prevalence and molecular characterization of tetracycline resistance in Enterococcus isolates from food. Appl. Environ. Microbiol. 70, 1555-1562.

Jackson, C. R., Fedorka-Cray, P. J., Davis, J. A., Barrett, J. B., Brousse, J. H., Gustafson, J. and Kucher, M. (2010): Mechanisms of antimicrobial resistance and genetic relatedness among enterococci isolated from dogs and cats in the United States. J. Appl. Microbiol. 108, 2171-2179.

Jouini, A., Ben Slama, K., Saenz, Y., Klibi, N., Costa, D., Vinué, L., Zarazaga, M., Boudabous, A. and Torres, C. (2009): Detection of multiple-antimicrobial resistance and characterization of the implicated genes in Escherichia coli isolates from food of animal origin in Tunis. J. Food Prot. 72, 1082-1088.

Klibi, N., Aouini, R., Borgo, F. C., Ben Said, L., Ferrario, C., Dziri, R., Boudabous, A., Torres, C. and Ben Slama, K. (2015a): Antibiotic resistance and virulence of faecal enterococci isolated from food-producing animals in Tunisia. Ann. Microbiol. 65, 1-8.

Klibi, N., Ben Amor, I., Rahmouni, M., Dziri, R., Gtari, D., Ben Said, L., Lozano, C., Boudabous, A., Ben Slama, K., Mansouri, R. and Torres, C. (2015b): Diversity of species and antibiotic resistance among fecal enterococci from wild birds in Tunisia. Detection of vanAcontaining Enterococcus faecium isolates. Eur. J. Wildl. Res. 61, 319-323.

Klibi, N., Ben Lagha, A., Ben Slama, K., Boudabous, A. and Torres, C. (2013a): Faecal enterococci from camels in Tunisia: species, antibiotic resistance and virulent genes. Vet. Rec. 172, 213.

Klibi, N., Ben Said, L., Jouini, A., Ben Slama, K., López, M., Ben Sallem, R., Boudabous, A. and Torres, C. (2013b): Species distribution, antibiotic resistance and virulence traits in enterococci from meat in Tunisia. Meat Sci. 93, 675-680.

Klibi, N., Ben Slama, K., Masmoudi, A., Gharbi, S., Ruiz-Larrea, F., Fendri, C., Boudabous, A. and Torres, C. (2006): Diversity of structures carrying the aac(6')-aph(2'”) gene in clinical E. faecalis and E. faecium strains isolated in Tunisia. J. Chemother. 18, 353-359.

Linaje, R., Coloma, M. D., Perez-Martinez, G. and Zuniga, M. (2004): Characterization of faecal enterococci from rabbits for the selection of probiotic strains. J. Appl. Microbiol. 96, 761-771.

López, M., Sáenz, Y., Rojo-Bezares, B., Martínez, S., del Campo, R., Ruiz-Larrea, F., Zarazaga, M. and Torres, C. (2009): Detection of vanA and vanB2-containing enterococci from food samples in Spain, including Enterococcus faecium strains of CC17 and the new singleton ST425. Int. J. Food Microbiol. 133, 172-178.

Marinho, C., Igrejas, G., Gonçalves, A., Silva, N., Santos, T., Monteiro, R., Gonçalves, D., Rodrigues, T. and Poeta, P. (2014): Azorean wild rabbits as reservoirs of antimicrobial resistant Escherichia coli. Anaerobe 30, 116-119.

Poeta, P., Costa, D., Rodrigues, J. and Torres, C. (2006): Antimicrobial resistance and the mechanisms implicated in faecal enterococci from healthy humans, poultry and pets in Portugal. Int. J. Antimicrob. Agents 27, 131-137.

Poeta, P., Costa, D., Saenz, Y., Klibi, N., Ruiz-Larrea, F., Rodrigues, J. and Torres, C. (2005): Characterization of antibiotic resistance genes and virulence factors in faecal enterococci of wild animals in Portugal. J. Vet. Med. 52, 396-402.

Ritchie, J. M., Thorpe, C. M., Rogers, A. B. and Waldor, M. K. (2003): Critical roles for stx2, eae, and tir in enterohemorrhagic Escherichia coli-induced diarrhea and intestinal inflammation in infant rabbits. Infect. Immun. 71, 7129-7139.

Sáenz, Y., Brinăs, L., Domínguez, E., Ruiz, J., Zarazaga, M., Jordi, V. and Torres, C. (2004): Mechanisms of resistance in multiple-antibiotic-resistant Escherichia coli strains of human, animal and food origins. Antimicrob. Agents Chemother. 48, 3996-4001.

Sáenz, Y., Zarazaga, M., Briňas, L., Lantero, M., Ruiz-Larrea, F. and Torres, C. (2001): Antibiotic resistance in Escherichia coli isolates obtained from animals, foods and humans in Spain. Int. J. Antimicrob. Agents 18, 353-358. 
Santos, T., Silva, N., Igrejas, G., Rodrigues, P., Micael, J., Rodrigues, T., Resende, R., Gonçalves, A., Marinho, C., Gonçalves, D., Cunha, R. and Poeta, P. (2013): Dissemination of antibiotic resistant Enterococcus spp. and Escherichia coli from wild birds of Azores Archipelago. Anaerobe 24, 25-31.

Sayah, R. S., Kaneene, J. B., Johnson, Y. and Miller, R. (2005): Patterns of antimicrobial resistance observed in Escherichia coli isolates obtained from domestic- and wild-animal fecal samples, human septage, and surface water. Appl. Environ. Microbiol. 71, 1394-1404.

Silva, N., Igrejas, G., Figueiredo, N., Gonçalves, A., Radhouani, H., Rodrigues, J. and Poeta, P. (2010): Molecular characterization of antimicrobial resistance in enterococci and Escherichia coli isolates from European wild rabbit (Oryctolagus cuniculus). Sci. Total Environ. 408, 4871-4876.

Teshager, T., Herrero, I. A., Porrero, M. C., Garde, J., Moreno, M. A. and Doměnguez, L. (2000): Surveillance of antimicrobial resistance in Escherichia coli strains isolated from pigs at Spanish slaughterhouses. Int. J. Antimicrob. Agents 15, 137-142.

Torres, C., Tenorio, C., Portillo, A., Garcia, M., Martínez, C., del Campo, R., Ruiz-Larrea, F. and Zarazaga, M. (2003): Intestinal colonization by $\operatorname{van} \mathrm{A}$ or $\operatorname{van} \mathrm{B} 2$-containing enterococcal isolates of healthy animals in Spain. Microb. Drug Resist. 9, 47-52.

Turabelidze, D., Kotetishvili, M., Kreger, A., Morris, J. G. and Sulakvelidze, A. (2000): Improved pulsed-field gel electrophoresis for typing vancomycin-resistant enterococci. J. Clin. Microbiol. 38, 4242-4245.

Van den Bogaard, A. E. and Stobberingh, E. E. (2000): Epidemiology of resistance to antibiotics. Links between animals and humans. Int. J. Antimicrob. Agents 14, 327-335. 